\title{
DISEASES CAUSED BY POXVIRUS - ORF AND MILKER'S NODULES - A REVIEW
}

\section{BARRAVIERA, S.R.C.S. $(1,2)$}

(1) Department of Dermatology and Radiotherapy, Botucatu School of Medicine, São Paulo State University (UNESP), Botucatu, São Paulo, Brazil.

(2) Center for the Studies of Venoms and Venomous Animals (CEVAP), UNESP, Botucatu, São Paulo, Brazil.

ABSTRACT: Sheep and cattle parapoxviruses cause in human beings diseases of very similar aspect, named orf and milker's nodules, respectively. These infections are generically called farmyard pox. In the present article, we show the epidemiological, clinical, and histopathological aspects, as well as the treatment of these two viral diseases that are very similar, being differentiated only by their epidemiological aspects.

KEY WORDS: orf, milker's nodules, Poxvirus.

\section{CORRESPONDENCE TO:}

S.R.C.S. BARRAVIERA, Centro de Estudos de Venenos e Animais Peçonhentos (CEVAP), UNESP, Caixa Postal 577, 18618-000, Botucatu, São Paulo, Brasil. Phone: 55143815 3963. Email: srbarraviera@cevap.org.br 


\section{INTRODUCTION}

Sheep and cattle parapoxvirus infections cause in human beings diseases of very similar aspect named orf and milker's nodules, respectively. These infections are generically called farmyard pox. They present identical clinical manifestations and histopathological alterations, being differentiated only by the epidemiological findings. Thus, the diagnosis of these two infections is based on a highly detailed anamnesis.

\section{MILKER'S NODULES}

Also known as paravaccinia or pseudocowpox, milker's nodule is an occupational disease of milkers and veterinarians, also affecting people that handle fresh meat. It is endemic among cattle, causing lesions in the udder, trunk, legs and oral cavity as a bovine papular stomatitis $(2,3,5)$

Human infection is accidental, occurring when men come into contact with infected animals or handle meat contaminated by the virus. Human-to-human transmission has not been described yet. The incubation period varies between 5 and 15 days $(1,2,4)$.

Clinically, the lesion manifests in flattened erythematous papules, which, after some days, change to firm violaceous erythematous nodules. The skin becomes opaque and grayish with small crusts, and central depression (Figures 1 and 2 ). Generally, there is erythema surrounding the nodules (Figures 3 and 4). In most cases there are from two to five nodules that can be solitary or numerous, more frequently located in the hands, particularly in the fingers, and occasionally in the face (Figures 5 and 6) $(2,4)$.

Some patients may develop lymphangitis or simile multiform erythema secondary to the infection (Figure 7) (2, 4).

As previously described, the disease affects individuals who come into direct and frequent contact with infected animals, such as bovine milkers, veterinarians, butchers, and cooks, which also handle fresh meat (6).

Differential diagnoses include pyogenic granuloma, sporotrichosis and orf, among others (3).

The disease diagnosis is based on the patient's history, clinical signs, histopathology, and electron microscopy. Histopathology shows hyperkeratosis, parakeratosis, and acanthosis of the epidermis, which generally presents multilocular vesicles, reticular 
degeneration and balloon-shaped cells. Eosinophilic inclusion bodies in the cytoplasm of vacuolated epidermic cells are characteristic, but not observed in all the stages of the disease. The dermis shows inflammatory infiltrate, predominantly mononuclear, and high quantity of eosinophils. Even in the absence of inclusions, the virus can be demonstrated by electron microscopy, where it appears in a cylindrical form. It is essentially formed of DNA, involved by a less dense capsule and measures 140x310nm; generally, the mature viral particles are located in the corneal layer (Figures 8 and 9) (4, 5).

Clinical signs spontaneously resolve in 6-8 weeks, leaving no scars. Some authors recommend symptomatic treatment when necessary, besides curettage and cauterization (8).

Prevention consists of treating the cows' mastitis, as well as using gloves, soap, water, and disinfectants before and after milking or handling these animals (6).

\section{ORF}

Orf is also known as ecthyma contagiosum, contagious pustular dermatitis, sheep-pox, and infectious labial dermatitis. It is common in areas inhabited by sheep.

Infection by the orf virus was first described in sheep by Steeb in 1787 and in goats in 1879. The first case in humans was reported by Newson and Cross in $1934(1,4,5,7)$.

The orf virus belongs to the poxviruses family and Parapoxvirus genus. It is cylindrical, with diameter ranging between 140-170 x 200-300 nm, and contains double-chain DNA. Its genomic sequencing has revealed that the genes most probable to induce virulence and immunity are concentrated at the terminal regions. The virus is resistant to ether and other lipid solvents, and is inactivated if under $30^{\circ} \mathrm{C}$ for 30 minutes (1).

This virus mainly infects sheep and goats, being transmitted by direct contact with fomites such as grassland, especially preferred by young animals. The incidence of this infection is higher at the end of spring (1).

Transmission to man occurs via the contact with wounded skin zones in infected animals or fomites. It is more frequent among milkers, veterinarians, butchers, herders and people who come into contact with infected animals; being considered as a professional disease $(1,7)$. 
Previous contamination does not provide permanent immunity, although less severe infections have been described in cases of reinfection.

Direct transmission of active lesions is more common, but contamination through fomites is frequent, since the virus is resistant to heat. Autoinoculation may occur but human-tohuman transmission is rare $(1,4)$.

Its incubation period is approximately one week, and clinically it is presented in several stages, as described: initially the lesion starts as a papule, target lesion, erythematous center, surrounded by a whitish ring and erythematous halo ( Figures 10, 11, 12 e 13). After, in the acute stage, a nodule similar to an erythematous pyogenic granuloma appears. In the third phase, in hair-bearing surface, there is temporary alopecia. In the regenerative phase, the lesion becomes dry, with black dots in the surface. The nodule changes to papillomatous and flattened, forms a dry crust, and rarely leaves scars $(1,5$, 7).

Lesions are generally smaller than one centimeter; except in immunosuppressed individuals, in which they can become giant.

Recovery is spontaneous in approximately six weeks. The lesion may be accompanied by edema, fever, ache, and lymphangitis, generally less severe than those of cowpox. It may be associated to simile multiform erythema in $5 \%$ cases.

Diagnosis is based on the patient's history, clinical signs, histopathology, and electron microscopy $(1,4,5,7)$.

The histopathological findings correlate with the clinical signs. Thus, the nodules present pseudoepitheliomatous hyperplasia with parakeratosic crust. The keratocytes always show virotic alterations of cytoplasmatic and nucleolar vacuolization with eosinophilic inclusions surrounded by a whitish halo. The papillary dermis is markedly edematous, presenting dense and extensive dermic infiltrate interfacing with the deep dermis and composed of lymphocytes, histiocytes, neutrophils and eosinophils. There is intense capillary proliferation and dilatation in the outer dermis (1).

Treatment is palliative, and shave excision may accelerate the process (8)

Thus, both parapoxvirus diseases are very similar regarding the clinical and histopathological aspects, differentiated only by the epidemiological aspects. 
Probably there are many more cases than the ones described in literature $(2,7)$, since people from the rural area know the disease and rarely ask for medical care.

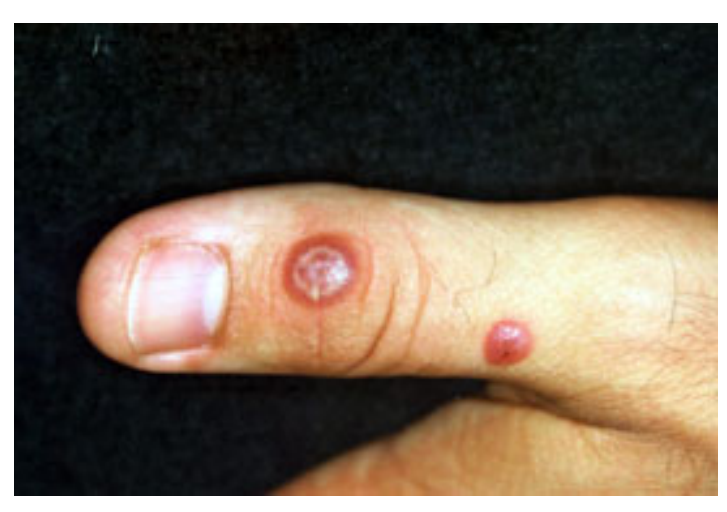

Figure 1: Presence of two violaceous erythematous lesions with central depression.

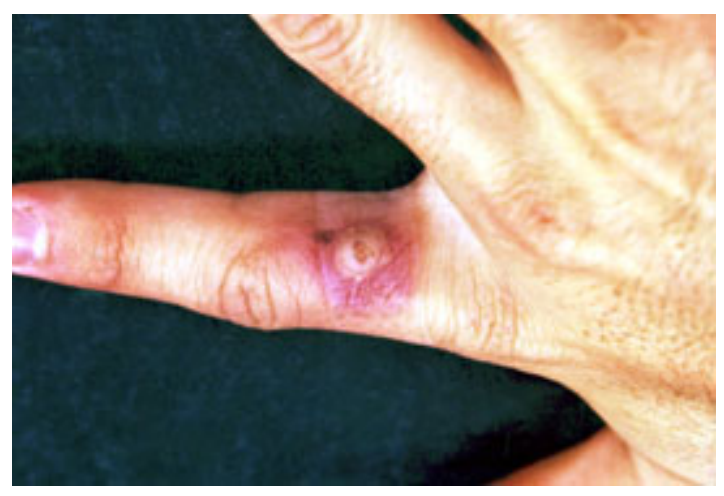

Figure 3: Umbilicated lesions surrounded by erythema.

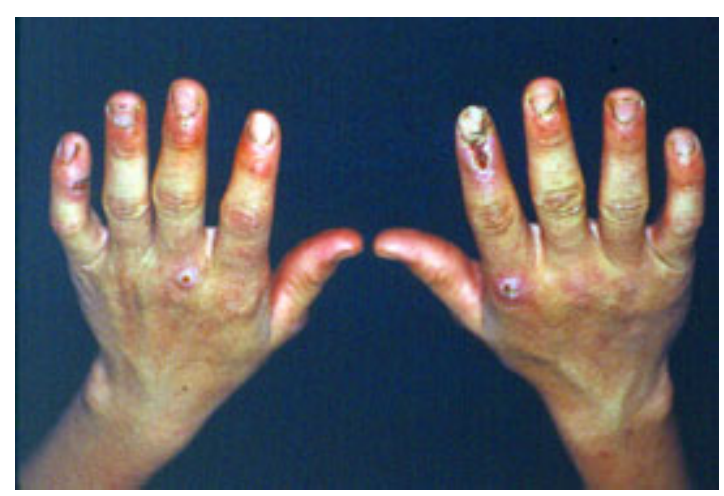

Figure 5: Multiple lesions affecting both hands.

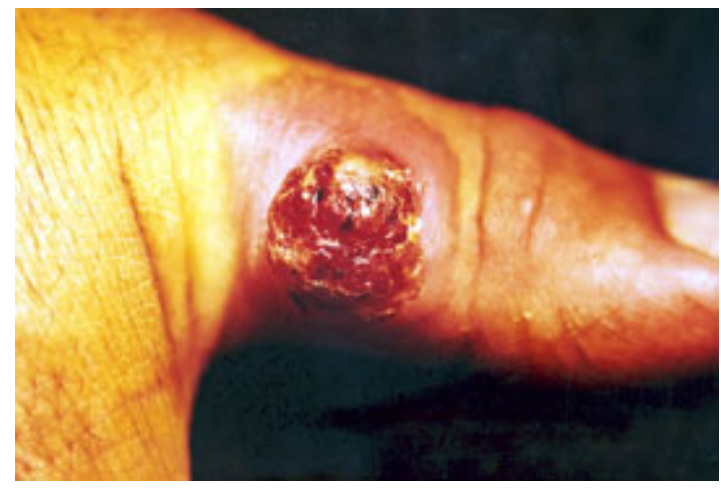

Figure 2: Ulcerated nodule with small crusts in its surface.

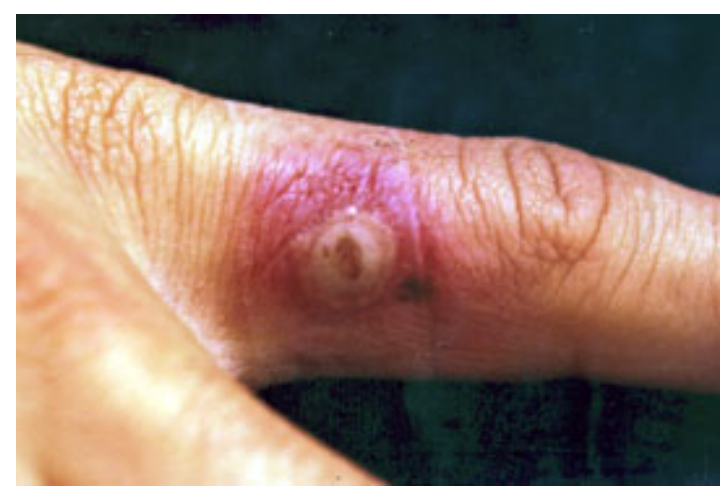

Figure 4: Detail of the lesion showing the erythematous center.

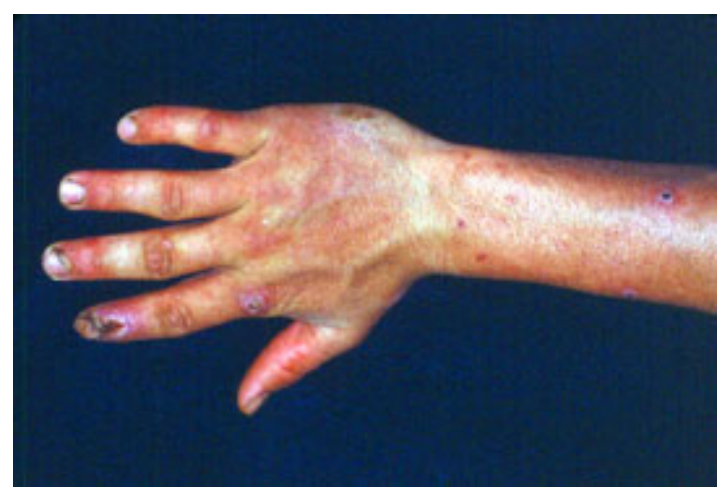

Figure 6: Multiple lesions. 


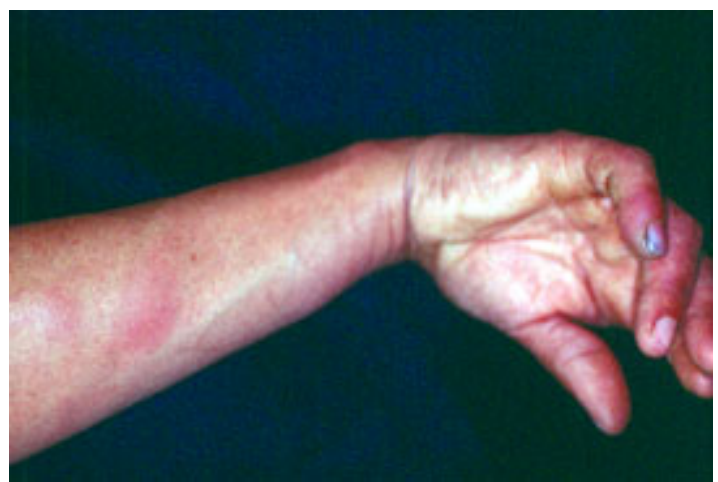

Figure 7: Lymphangitis secondary to the infection.

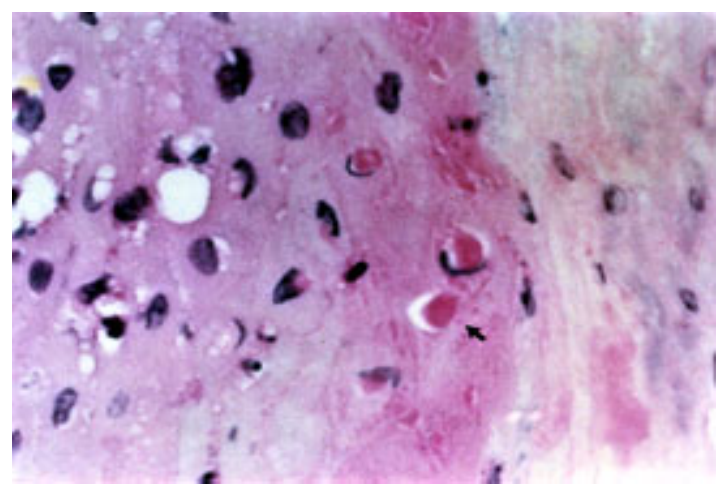

Figure 9: Keratinocytes with eosinophilic inclusions in the cytoplasm.

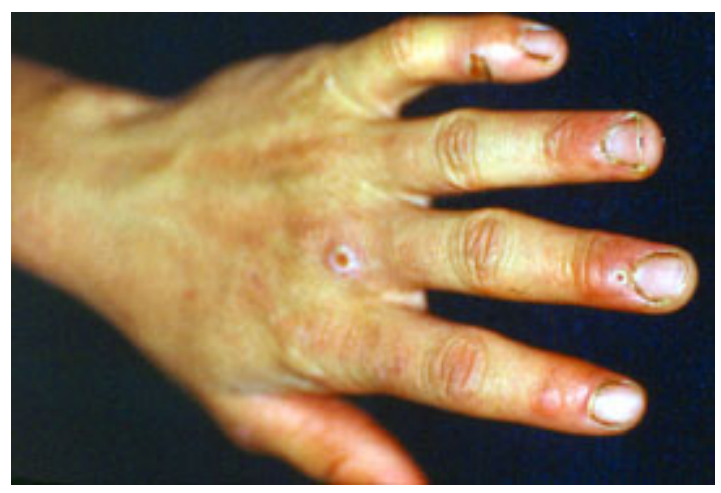

Figure 11: Umbilicated lesion and presence of inflammation in the ungual folds.

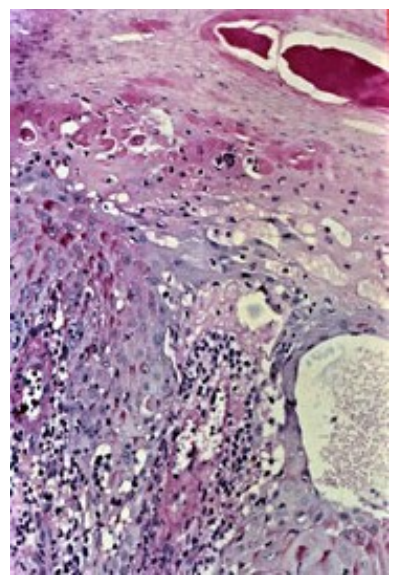

Figure 8: Histological alterations characteristic of this disease.

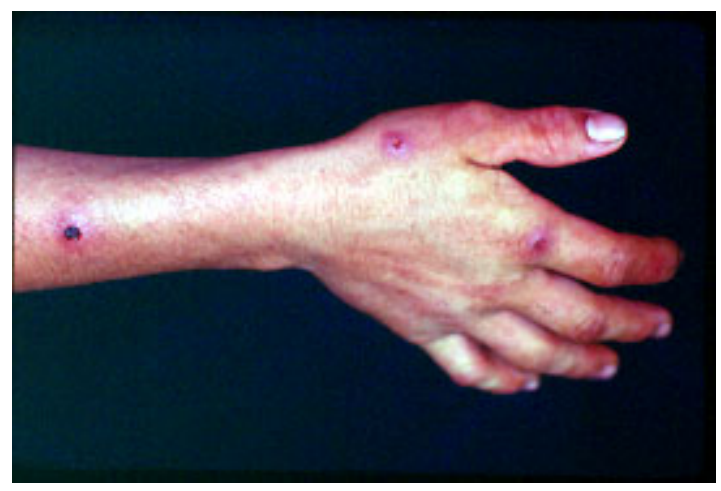

Figure 10: Multiple violaceous erythematous lesions, some of them are umbilicated.

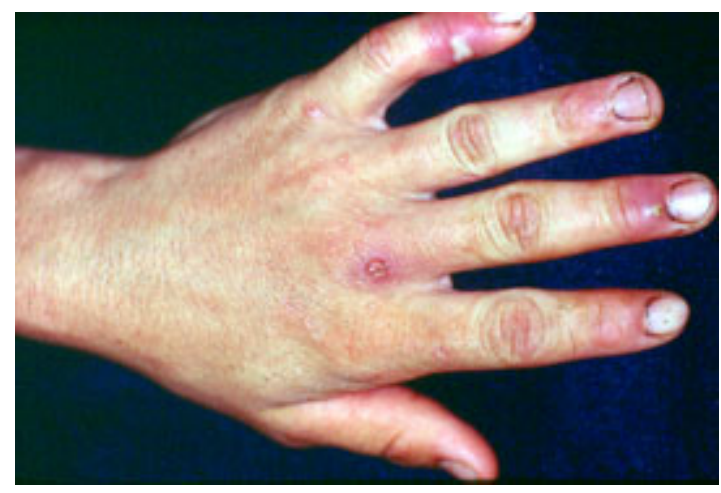

Figure 12: Presence of important erythema and pustular lesion in the fifth finger. 


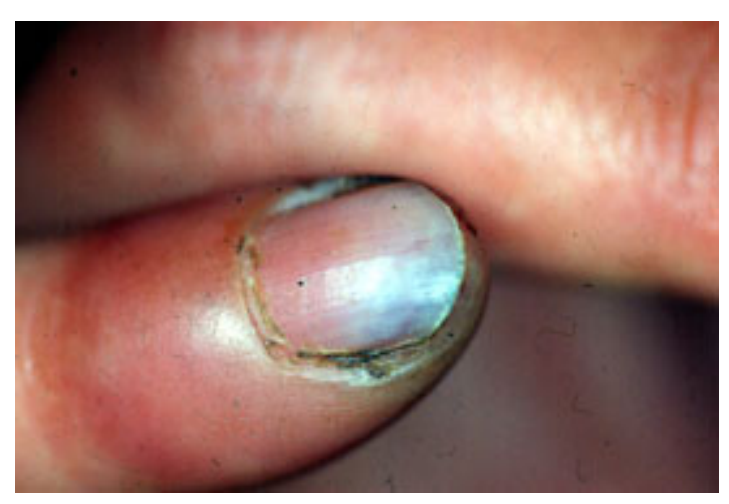

Figure 13: Edema and erythema in the ungual folds.

\section{REFERENCES}

1 ARRANZ, FR., ARIAS, CA, RUBIO, JFP. Infeccion por vírus orf. Piel., 2000, 15, 367 71.

2 BARRAVIERA, SRCS., MARQUES, SA. , STOLF, HO., SILVARES, MRC., MARQUES, MEA. Nódulos dos ordenhadores: relato de dez casos. An. bras. Dermatol., 1997, 72, 477-80.

3 BARRAVIERA, SRCS. Nódulos dos ordenhadores. In: DIÓGENES, MJN, GONÇALVES, HS, TALHARI, S., NEVES, R.G. Ed. Atlas de Dermatopatologia Tropical. Rio de Janeiro: MEDSI, 2001, 260-63.

4 DUPRE, A., AUVERGNAT, J., DURAND, R, CATALA, D. Orf and milker's nodules. Ann. Dermatol. Venereol., 1978, 105, 213-4,

5 GROVES, RW., WILSON-JONES, E., MAC DONALD, DM. Human orf and milker's nodule: a clinicopathologic study. J. Am. Acad. Dermatol., 1961, 25, 2813-8.

6. LEAVELL, UW., PHILLIPS, JA. Milker's nodules. Pathogenesis, tissue culture, electron microscopy and calf inoculation. Arch. Dermatol., 1975, 111, 1307-11.

7. LEAVELL, UV., MAC NAMARA, MJ. MUELLING, R., TALBERT, WM., RUCKER, RC., DALTON, AJ. Orf. Report of 19 human cases with clinical and pathological observations. J. Am. Med. Assoc., 1968, 204:109-16.

8. SHELLEY, WD., SHELLEY, ED. Surgical treatment of farmyard pox: orf, milker's nodule, bovine pustular stomatites pox. Cutis, 1983, 31, 25657. 